\title{
BMJ Open Prescribing patterns for medical treatment of suspected prostatic obstruction: a longitudinal register- based study of the Scottish Health and Social Care Open Data
}

\author{
Federico Andreis (1) , ${ }^{1}$ Richard Bryant, ${ }^{2,3}$ Emanuele Giorgi, ${ }^{4}$ Andrea E Williamson, ${ }^{5}$ \\ Ashleigh Ward ${ }^{6}$
}

To cite: Andreis F, Bryant R, Giorgi E, et al. Prescribing patterns for medical treatment of suspected prostatic obstruction: a longitudinal register-based study of the Scottish Health and Social Care Open Data. BMJ Open 2021;11:e042606. doi:10.1136/ bmjopen-2020-042606

- Prepublication history and additional materials for this paper is available online. To view these files, please visit the journal online (http://dx.doi. org/10.1136/bmjopen-2020042606).

Received 09 July 2020 Revised 26 December 2020 Accepted 13 January 2021

Check for updates

(C) Author(s) (or their employer(s)) 2021. Re-use permitted under CC BY-NC. No commercial re-use. See rights and permissions. Published by BMJ.

For numbered affiliations see end of article.

Correspondence to

Dr Federico Andreis;

federico.andreis@stir.ac.uk

\section{ABSTRACT}

Background The diagnosis of lower urinary tract symptoms related to suspected bladder outflow obstruction from benign prostate hyperplasia/enlargement in men is increasing. This is leading to high demand on healthcare services; however, there is limited knowledge of differences in pharmacotherapy prescribing for this condition based on geography.

Objective To investigate potential variation in drug prescribing for suspected bladder outflow obstruction in Scotland, based on analysis of publicly available data, to identify trends and inform future prescribing.

Study design A longitudinal register-based data study of prescribing and patient data publicly available from Scottish registries. All information is available as monthly aggregates at the level of single general practices.

Setting and participants $903(97 \%)$ general practices in Scotland, over a 50-month period (October 2015 to November 2019).

Outcome measurements and statistical analysis We analysed numbers of daily doses of drugs for suspected bladder outflow obstruction prescribed per month using a Bayesian Poisson regression analysis, incorporating random effects to account for spatial and temporal elements.

Results Prescriptions for suspected bladder outflow obstruction medications increased during the observation period (overall average rate of change $1.24 \pm 0.28$, ranging from 0.893 in Orkney to 1.95 in Lanarkshire). While some determinants of health inequality regarding prescribing practices across health boards are consistent with those known from the literature, other inequalities remain unexplained after accounting for practice-specific and patient-specific characteristics such as deprivation and rurality.

Conclusions Inequalities in prescribing for suspected bladder outflow obstruction medications exist in Scotland, partially ascribable to accepted sociodemographic and geographic factors.

\section{INTRODUCTION}

The incidence of bothersome lower urinary tract symptoms (LUTS) in men, which are
Strengths and limitations of this study

- This is the first study to investigate spatial and temporal variations in drug-prescribing patterns for bladder outflow obstruction using geostatistical models.

- As such, this data provide a new perspective to inform clinical practice.

- The statistical framework described in this paper is very general and can be readily extended to other settings and conditions.

- Data on drug prescribing in Scotland only exist in the public domain at an aggregate (ie, individual general practitioners' practice or patient list) level, which limits the granularity of the analysis.

- The use of summary data regarding levels of socioeconomic deprivation and rurality of patients reduces the accuracy with which one can estimate the shape of their association with the outcome. These factors are likely to be important in terms of access to healthcare and prescribing.

predominantly attributable to benign prostate hyperplasia (BPH) and/or benign prostatic enlargement causing proven or suspected bladder outflow obstruction (BOO), is increasing globally, resulting in reduced quality of life and increased healthcare expenditure. ${ }^{12}$ In Scotland, men with suspected or proven BOO are generally managed in primary care with medication prescribed by general practitioners (GPs) and/or specialist practitioners, with such medication either prescribed by GPs alone or as part of shared care with specialists such as urologists. ${ }^{1}$ Scottish healthcare services, that treat men with prostate conditions face increased demand resulting from an ageing population, increased prostate cancer $(\mathrm{PCa})$ investigation $^{34}$ and increased awareness of men's health issues, which is likely to have 
impacted on the care of men with bothersome LUTS arising from BOO. Studies reporting the incidence and prevalence of LUTS in men are predominantly crosssectional in nature, with widely varying results. ${ }^{5}$

Scotland's diverse geography provides an ideal landscape to understand how factors that may impact on prescribing patterns may differ spatially in terms of geography and longitudinally. ${ }^{6}$ Prescribing trends in Scotland vary geographically by urban/rural and sociodemographic classifications ${ }^{6}$ and by unique regional cultures or as a result of strong 'social patterning', one example being the so-called 'Glasgow effect'. ${ }^{78}$ Furthermore, it has been acknowledged that aspects regarding individual GP medical practices may contribute to prostate health inequalities across UK. ${ }^{9} 10$

Data regarding the prescription of drugs for the medical management of BOO as a cause for male bothersome LUTS have been used internationally in recent years to increase the understanding of patterns of prescribing within specific populations. This approach can be useful to identify potential demographic inequalities in patient access to healthcare for this condition and to understand the patient experience, predominantly using longitudinal data sets. ${ }^{11-13}$ However, to date, there is limited knowledge of how the prescribing patterns for drugs used to treat BOO may differ both spatially and temporally. The increasing availability of high-quality open access healthcare data in Scotland has created the opportunity for a more refined and broader-based analysis of prescribing patterns for BOO.

We investigated the possibility that differences may exist in Scotland in the prescribing patterns of the two main classes of medications used to treat bothersome LUTS secondary to BOO. We performed an analysis of publicly available data in order to identify possible variations in prescribing trends that may help inform future prescribing practice.

\section{MATERIAL AND METHODS \\ Data sources}

Data were acquired and linked from numerous independent and publicly accessible sources. The data set comprised information at the level of individual general practices and was created from the following four sources:

1. National Health Service (NHS) Scotland OpenData: drug prescriptions monthly data (https://www.opendata.nhs.scot/dataset/prescriptions-in-the-community).

2. Information Services Division Scotland (ISD): practice details, deprivation, rurality (https://www.isdscotland. org/Health-Topics/General-Practice/).

3. National Institute for Health and Care Excellence (NICE): daily dosages (https://www.nice.org.uk).

4. National Records of Scotland (NRS): postcodes, health boards (https://www.nrscotland.gov.uk/statistics-anddata/geography/our-products/scottish-postcode-directory/2018-2).
Table 1 Variables extracted from the four data sources and used as covariates in the statistical model

\begin{tabular}{|c|c|c|}
\hline Variable & Type & Short description \\
\hline Drug group & Categorical & $\begin{array}{l}\alpha-1 \text { blocker or } 5-\alpha \text { reductase } \\
\text { inhibitor }\end{array}$ \\
\hline $\begin{array}{l}\text { GP patient } \\
\text { list size }\end{array}$ & $\begin{array}{l}\text { Numerical, } \\
\text { time-varying }\end{array}$ & $\begin{array}{l}\text { Number of registered patients } \\
\text { per GP practice }\end{array}$ \\
\hline $\begin{array}{l}\text { GP } \\
\text { practice } \\
\text { run }\end{array}$ & $\begin{array}{l}\text { Categorical, } \\
\text { baseline }\end{array}$ & $\begin{array}{l}\text { Is the practice run by GPs } \\
\text { (contract type } 17 \mathrm{~J} \text { and } 17 \mathrm{C} \text { ), } \\
\text { rather than by the NHS } \\
\text { (contract type } 2 \mathrm{C} \text { )? Yes/No }\end{array}$ \\
\hline $\begin{array}{l}\text { Dispensing } \\
\text { GP } \\
\text { practice }\end{array}$ & $\begin{array}{l}\text { Categorical, } \\
\text { baseline }\end{array}$ & $\begin{array}{l}\text { Does the GP practice } \\
\text { have a license to dispense } \\
\text { medicines? Yes/no }\end{array}$ \\
\hline Men 45+ & $\begin{array}{l}\text { Numerical, } \\
\text { time-varying }\end{array}$ & $\begin{array}{l}\text { Proportion of patients that are } \\
\text { men aged } \geq 45 \text { years }\end{array}$ \\
\hline $\begin{array}{l}\text { Deprived } \\
15\end{array}$ & $\begin{array}{l}\text { Numerical, } \\
\text { time-varying }\end{array}$ & $\begin{array}{l}\text { Proportion of patients under } \\
\text { the 15th national percentile of } \\
\text { deprivation (SIMD) }\end{array}$ \\
\hline Remote & $\begin{array}{l}\text { Categorical, } \\
\text { time-varying }\end{array}$ & $\begin{array}{l}\text { Modal rurality index among } \\
\text { the patients (Scottish } \\
\text { Government } 8 \text {-fold Urban } \\
\text { Rural Classification) recoded } \\
\text { as remote }(4,5,7,8) \text { or non- } \\
\text { remote }(1,2,3,6) \text {. Yes/no }\end{array}$ \\
\hline Postcode & $\begin{array}{l}\text { Categorical, } \\
\text { baseline }\end{array}$ & $\begin{array}{l}\text { GP practice postcode as of } \\
2019\end{array}$ \\
\hline $\begin{array}{l}\text { Health } \\
\text { board }\end{array}$ & $\begin{array}{l}\text { Categorical, } \\
\text { baseline }\end{array}$ & $\begin{array}{l}\text { Name of Scottish Health } \\
\text { Board where the GP practice } \\
\text { is situated. }\end{array}$ \\
\hline
\end{tabular}

GP, general practitioner; NHS, National Health Service; SIMD, Scottish Index of Multiple Deprivation.

The keys used to link the sources were the unique GP practice code and date. The ISD and NRS portals provided information regarding both the medical practice and their patient population. Table 1 contains a list of variables extracted from these sources. We used both deprivation and rurality to account for sociodemographic status. In particular, we used the 2016 Scottish Index of Multiple Deprivation ${ }^{14}$ and a recoded version of the 2018 Scottish Government Urban Rural Classification. ${ }^{15}$ In addition, the ISD and NRS sources provided GP practicelevel information regarding the size of the individual practice patient list, the gender and age distribution and the location of the practice (based on postcode and name of relevant Health Board). All GP practices open for the whole study period (October 2015 to November 2019) were included in the data set (903 of 944, 95.7\%, practices in Scotland open as of 1 January 2019). The Scottish Open Data portal provided the prescribed amounts of the drugs of interest per month.

\section{B00 medications analysed}

We specifically focused on the prescribing of $\alpha-1$ blocking drugs and $5-\alpha$ reductase inhibitors as these are the only 
Table 2 Suggested daily dosages of the study $\alpha-1$ blockers and $5-\alpha$ reductase inhibitors according to NICE guidelines

\begin{tabular}{lll}
\hline Drug & Drug group & $\begin{array}{l}\text { Suggested daily } \\
\text { dosage (NICE) }\end{array}$ \\
\hline Alfuzosin & $\alpha-1$ blocker & $\begin{array}{l}2.5 \mathrm{mg} \text { three times } \\
\text { a day } \\
10 \mathrm{mg} \text { once daily }\end{array}$ \\
\hline Tamsulosin cap/tab & $\alpha-1$ blocker & $400 \mathrm{mcg}$ once daily \\
Dutasteride & $\begin{array}{l}5-\alpha \text { reductase } \\
\text { inhibitor }\end{array}$ & 500 mcg once daily \\
Finasteride & $\begin{array}{l}5-\alpha \text { reductase } \\
\text { inhibitor }\end{array}$ & $5 \mathrm{mg}$ once daily \\
\hline
\end{tabular}

NICE, National Institute for Health and Care Excellence.

specific medications used for BOO. $\alpha-1$ blockers are the firstline and most commonly used drugs prescribed for LUTS secondary to BOO,${ }^{116}$ while 5 - $\alpha$ reductase inhibitors are generally recommended where men are considered at high risk of $\mathrm{BPH}$ progression due to a significantly enlarged prostate, either as monotherapy or in combination with $\alpha-1$ blockers. ${ }^{16} 17$ The $\alpha-1$ blockers alfuzosin and tamsulosin hydrochloride were included in the study; however, doxazosin and terazosin were not included as the amounts of these drugs prescribed were negligible, while doxazosin may be prescribed for hypertension. The 5- $\alpha$ reductase inhibitors, dutasteride and finasteride, were both included in this study. When combined with the suggested daily dosages from the NICE website (see table 2), a proxy for the number of daily doses was constructed by rounding to the nearest integer the following expression:

$$
n_{d t i}=\frac{\# \text { tablets of drug } d \text { prescribed during month } t \text { at practice } i}{\text { daily suggested dosage for drug } j} \#
$$

where i, d, and t represent the GP practice, drug and month, respectively. In our data set, we have observations for $\mathrm{i}=1, \ldots, 903$ GP practices over $\mathrm{t}=1, \ldots, 50$ months; $d$ indexes the drugs reported in table 2. The number of daily doses for each of the drug groups was then constructed by summation of the respective drugs' monthly amounts of daily doses. We denote with $\mathrm{n}_{\mathrm{jti}}$ the number of daily doses of drugs belonging to group $j \in\{\alpha 1-$ blocker, $5-\alpha$ reductase inhibitor $\}$, prescribed during month $\mathrm{t}$, at each GP practice i.

We then used a Poisson model in order to describe the average number of daily doses of BOO medication prescribed each month, accounting for each of the covariates presented in table 1 , with additional spatial and temporal random effects. Possible interactions between individual GP practices' prescribing patterns, or geographical location, with the prescribed drug type were also investigated.

Equation 1 describes the model's functional form, while table 3 summarises our choices in terms of spatial and temporal structure. Further details of the statistical analysis are provided as supplementary material.
Table 3 Spatial and temporal random effects

\begin{tabular}{lll}
\hline Parameter & Type & Short description \\
\hline$\alpha_{[i]}$ & Spatial & $\begin{array}{l}\text { Intrinsic conditional auto- } \\
\text { regressive }\end{array}$ \\
$\alpha_{[i]]}$ & Unstructured & $\begin{array}{l}\text { Unstructured interaction } \\
\text { between GP practice and drug } \\
\text { type }\end{array}$ \\
$\alpha_{[t \mathrm{tj}]}$ & Temporal & $\begin{array}{l}\text { First-order auto-regressive, } \\
\text { grouped by health board and } \\
\text { drug type }\end{array}$ \\
& &
\end{tabular}

GP, general practitioner.

$$
\begin{aligned}
& n_{[j t i]} \operatorname{Poisson}\left({ }_{[j i t]}\right) \\
& \log \left(\lambda_{\mathrm{jti}}\right)=\alpha+\alpha_{[\mathrm{i}]}+\alpha_{[\mathrm{ji}]}+\alpha_{[\mathrm{iji}]}+\beta_{1} \log \left(\text { list size }_{\mathrm{ti}}\right) \\
& +\beta_{2} \text { drug group }+\beta_{3} \text { contract }_{i}+\beta_{4} \text { dispensing }_{i} \\
& +\beta_{5} \text { males } 45 \mathrm{p}_{\mathrm{ti}}+\beta_{6} \text { deprived } 15_{\mathrm{ti}}+\beta_{7} \text { remote }_{\mathrm{ti}} \#
\end{aligned}
$$

where $\mathrm{j}$ (drug group), t (month) and i (each GP practice) are as described, and $\alpha_{[i]}, \alpha_{[j i]}, \alpha_{[t i]]}$ denote the random effects, summarised in table 3. A detailed discussion of the choice of the random components of the model is available in online supplemental file 1).

\section{Computational analysis}

All computational analyses were carried out in $\mathrm{R} 3.6 .1 .^{18}$ We estimated the model parameters within the Integrated Nested Laplace Approximation framework using the inla package. ${ }^{19}$ The code is available as online supplemental file 2, while data and shapefiles are from an external repository. ${ }^{20}$

\section{RESULTS}

We investigated the effects of each of the available covariates (including GP practice patient list size; BOO drug group; whether the practice was GP run; whether the GP practice dispensed medication; proportion of men aged 45 years; higher proportion of socioeconomic deprivation and remote/rural location) on the study outcome. Table 4 contains summary statistics on the sample.

Table 5 summarises the output of the Poisson regression estimates of each of the associated parameters. In a further analysis, we interpreted each of these parameters in terms of relative differences from the model average (with the exception of GP practice list size).

The GP practice patient list size was observed to have an effect consistent with an estimated increase of slightly less than one daily dose per month per additional patient (point estimate 0.915). As expected, the prescribed doses of the $5-\alpha$ reductase inhibitor drug group were observed to be on average less than the prescribed doses of the $\alpha-1$ blocker drug group. The estimated relative difference was calculated to be on average $45 \%-48 \%$ fewer $5-\alpha$ reductase inhibitor drug prescriptions than $\alpha-1$ blocker drug prescriptions per month (point estimate $46 \%$ ). 
Table 4 Summary statistics of the sample, stratified by health board

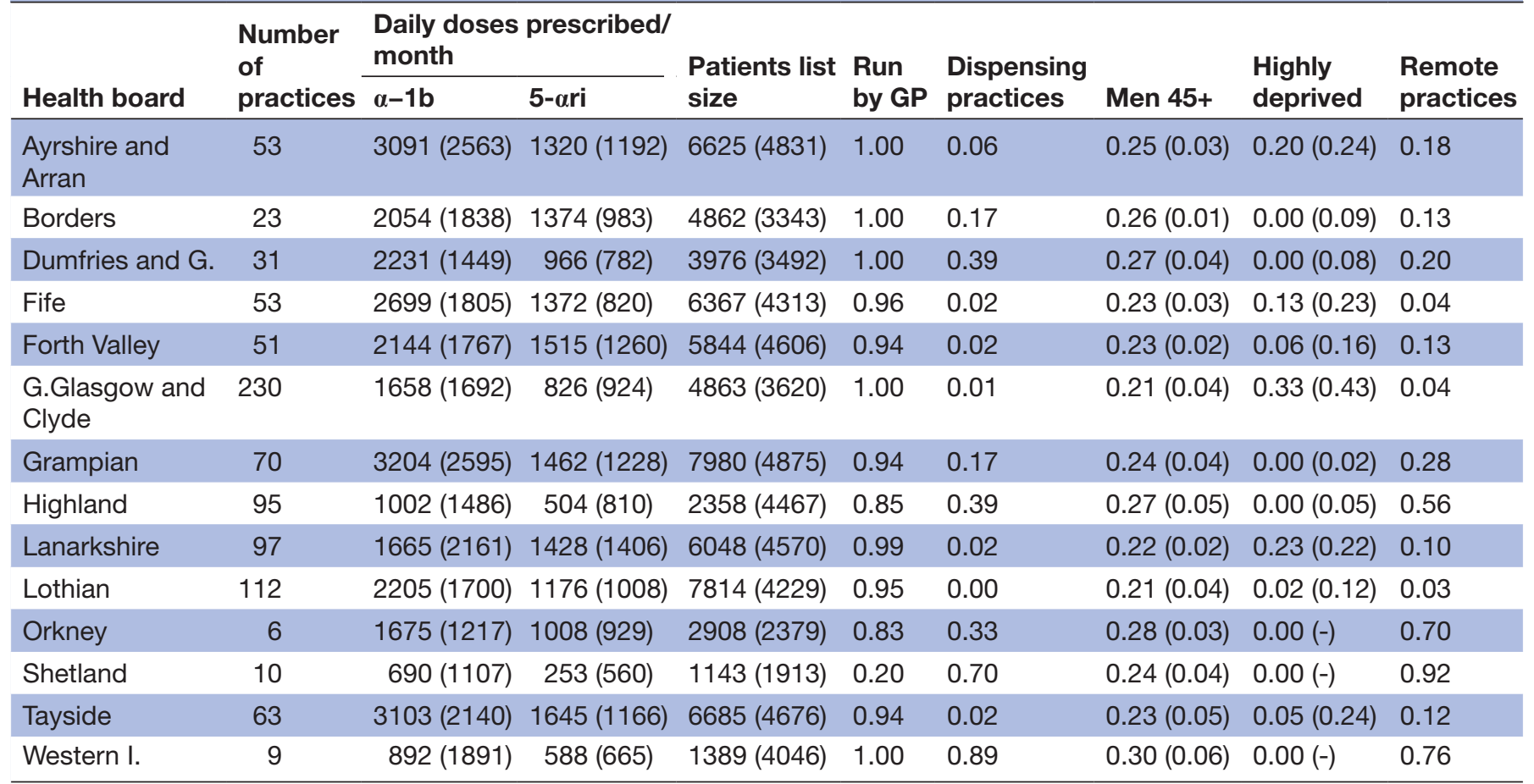

Number of practices, median and (IQR) for continuous variable, proportions for categorical variables. Counts are rounded to the nearest integer, proportions to the second decimal place.

GP, general practitioner.

We observed that the nature of how the GP practices are individually run is associated with BOO drug prescribing practice, with GP-run practices (rather than by direct NHS-run practices) having larger volumes of these prescriptions. The model results are consistent with 19\%-35\% (point estimate $27 \%$ ) increased number of monthly prescriptions for GP-run practices compared with NHS-run practices, all else being equal. This is an interesting result, and to the best of our knowledge, no rigorous research has been undertaken to investigate the role that how a GP practice is managed plays on the stability of provision of care and, in turn, on helpseeking behaviours and clinical outcomes. Conversely, we observed that GP-dispensing practices are associated with 3\%-13\% (point estimate $8 \%$ ) lower volumes of BOO drug prescriptions compared with GP practices without a pharmacy, keeping all other variables constant. Practices that dispense usually tend to do so because there is no local community pharmacy, and they need one to fit a need; one way of thinking about this is that having a dispensing licence may reflect an aspect of remoteness that is not captured by the rurality measure we employ.

Table 5 Summary of estimated posterior distributions for the fixed effects, containing the model estimates with associated uncertainty, on the rate ratio scale

\begin{tabular}{|c|c|c|c|c|c|c|}
\hline & Mean & SD & $2.5 \%$ & $50 \%$ & $97.5 \%$ & Mode \\
\hline$\alpha$-ilntercept & 0.208 & 0.008 & 0.192 & 0.208 & 0.225 & 0.208 \\
\hline$\beta_{1}-\log (\mathrm{GP}$ practice patient list size) & 0.915 & 0.002 & 0.911 & 0.915 & 0.919 & 0.915 \\
\hline$\beta_{3}-\mathrm{GP}$ run practices & 1.269 & 0.042 & 1.190 & 1.268 & 1.352 & 1.269 \\
\hline$\beta_{4}$-dispensing GP practice & 0.918 & 0.024 & 0.871 & 0.917 & 0.966 & 0.918 \\
\hline$\beta_{6}-$ socially deprived area & 1.017 & 0.007 & 1.003 & 1.017 & 1.031 & 1.017 \\
\hline$\beta_{7}-$ remote/rural GP practice & 1.002 & $<0.001$ & 1.002 & 1.002 & 1.003 & 1.002 \\
\hline
\end{tabular}

The posterior distribution associated to the patient list size effect estimate $\beta_{1}$ was not transformed and should be read on the outcome scale, as explained in-text.

GP, general practitioner. 


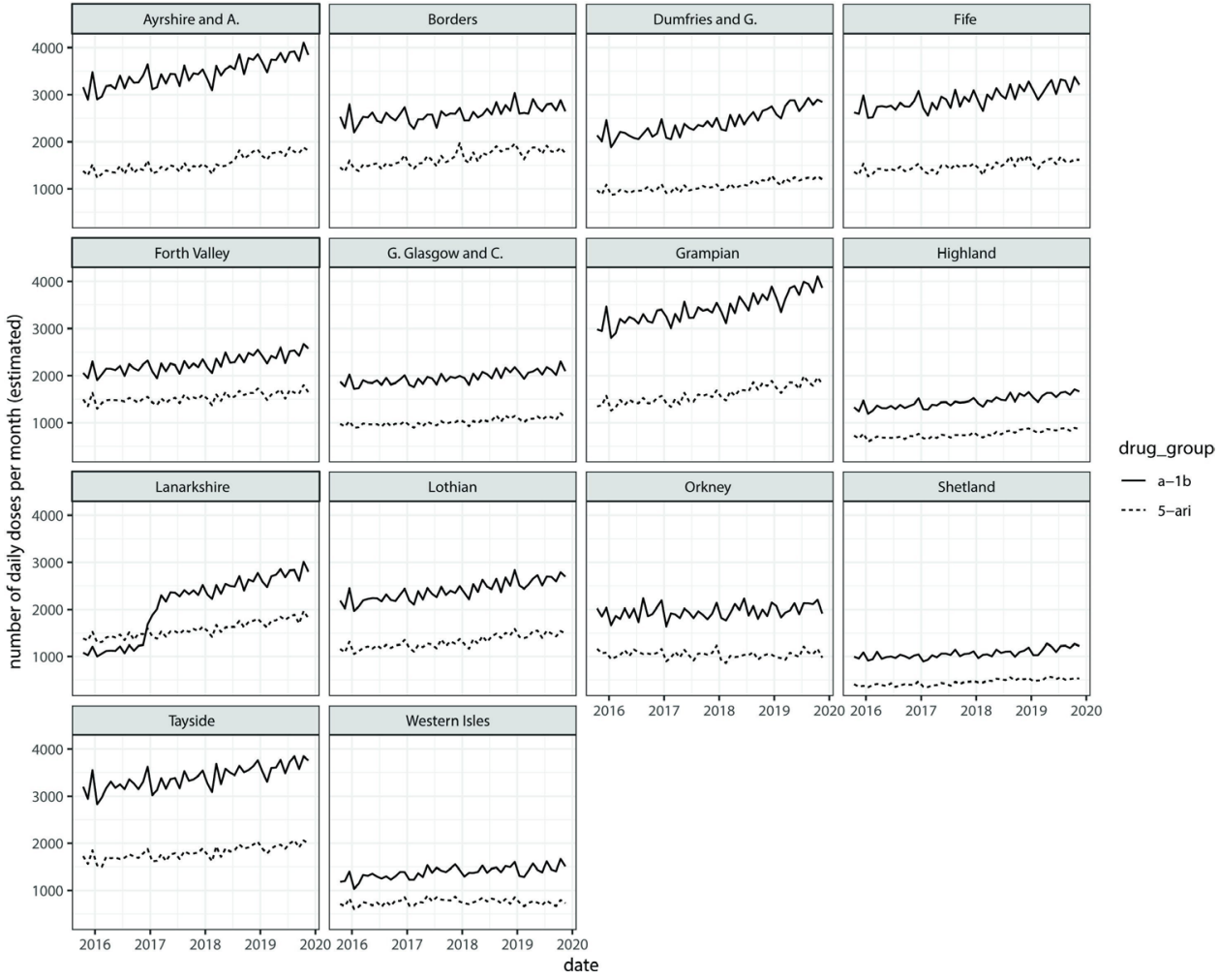

Figure 1 Statistical model average number of daily doses of each BOO drug type prescribed per month, by individual Scottish Health Board and adjusted for GP practice patient roll size. BOO, bladder outflow obstruction; GP,general practitioner.

We found the proportion of men aged $\geq 45$ years in the GP practice patient list to be positively associated with the volume of BOO prescriptions, with an estimated average increase in the monthly rate of prescription of $4.9 \%$ per percentage point. In contrast, the levels of deprivation, and a remote/rural geographical location of each GP practice, were found to have a negligible association with prescribing practice.

Next, we investigated the statistical model's interpolations according to Health Board and drug group ( $\alpha-1$ blocking drugs and 5- $\alpha$ reductase inhibitors) (figure 1). This analysis highlighted a general increase in the volumes of prescriptions for these medications over the 4-year study period. Trends in prescribing were observed to be broadly similar across most Health Boards, with a less prominent increase in less populated areas, which may potentially be attributable to a more stable population structure over the 4-year period of observation as well as unaccounted for differences in help-seeking behaviours. Within most Health Boards, the growth in prescriptions for each drug group was almost parallel during the 4-year observation period, suggesting consistency in terms of increased BOO drug prescribing. Additional observations included a marked shift in volumes of $\alpha-1$ blocking drug prescriptions in Lanarkshire between November 2016 and February 2017; however, no further specific information regarding this phenomenon was available within the publicly available data set. In the absence of a reasonable explanation for this singular observation in this one Health Board, this has been treated as an artefact due to a change in data-recording criteria.

Next, we investigated how the statistical model residuals may provide insight into how BOO drug prescribing behaviour differed across Scotland during the 4-year study period. Figure 2 illustrates histograms of exponentiated residuals for each individual Health Board across Scotland, where a reference value of $1=e^{0}$ represents a null residual (ie, there is no deviation from the model's predicted average). Each residual is specific to one individual anonymous GP practice. On an exponential scale, a value of 1 indicates a prescribing behaviour in line with the average as described by the statistical model across Scotland during the study period. A value below 1 indicates prescribing volumes higher than expected based on the model, while a value larger than 1 indicates prescribing volumes lower than expected. Asymmetry around the reference value of 1 , and/or multiple modes of distribution, suggests a different behaviour of individual GP practices within a Health Board compared against the national average across Scotland.

Using this statistical approach, we generally observed consistency in the prescription of drugs for BOO across Health Boards in Scotland, with most distributions appearing to be approximately unimodal and symmetric around the null residual (ie, the reference value of $1=e^{0}$ ). However, some interesting patterns of prescribing can be observed, such as the reduced level of BOO drug prescribing in some individual Health Boards (most 


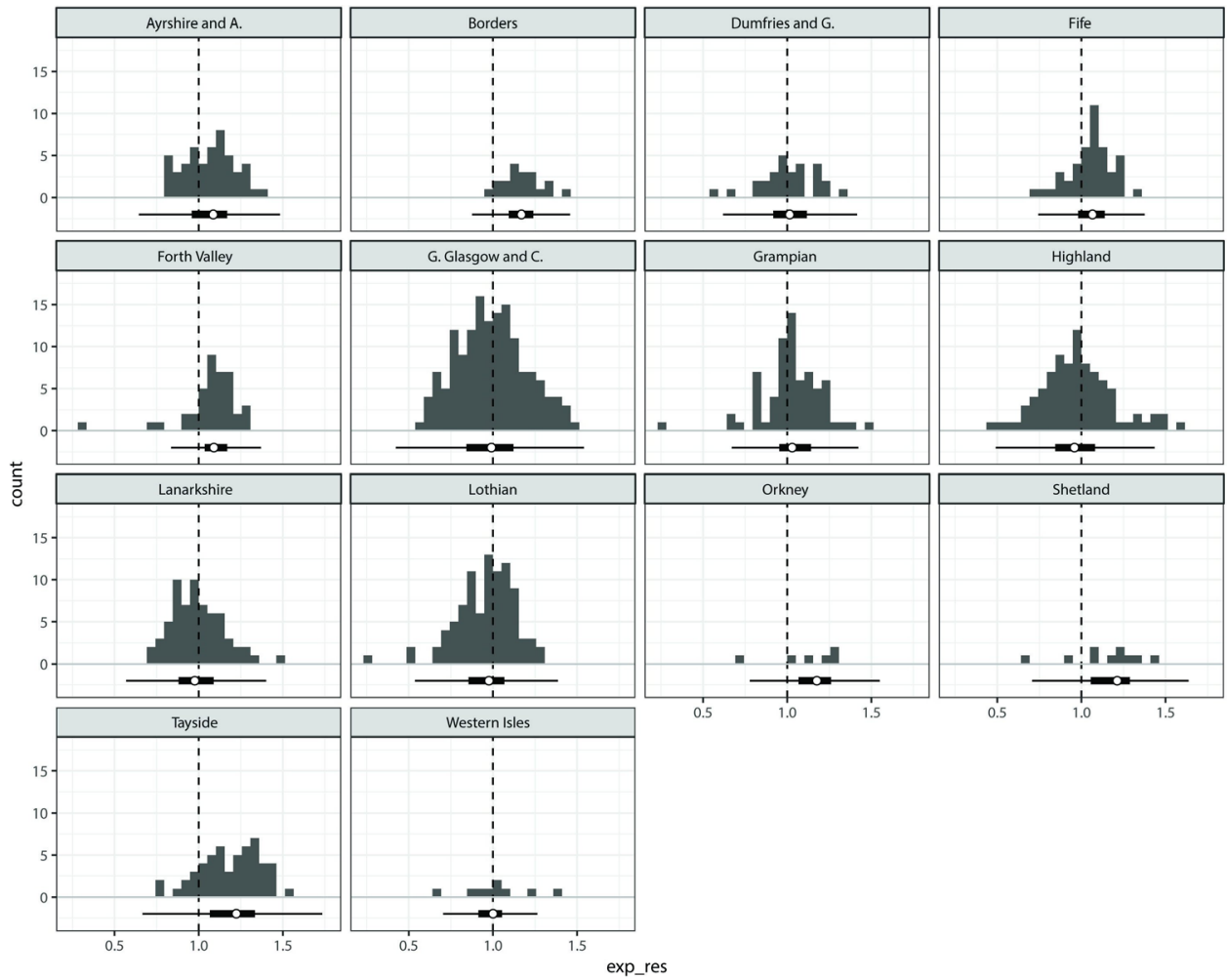

Figure 2 Frequency histograms of the statistical model's exponentiated residuals for each Scottish Health Board. The vertical dashed line represents the null residual (value $=1$ on the exponentiated scale), and each small black square represents the average number of daily prescriptions of BOO drugs (combined $\alpha-1$ blockers and 5- $\alpha$ reductase inhibitors) per month per individual anonymous GP practice within each Health Board. The boxplot below each histogram illustrates the same data distribution (the white point marks the median, the thick line represents the usual box and the thin line represents the whiskers). Ideally the exponentiated residuals for each GP practice would lie around the null residual (ie, value=1); however, the heterogeneity in prescribing practice is illustrated by increased spread to the left and right of the null residual. A shift of GP practice distributions to the right of the null residual, as seen in Health Boards such as Borders, Fife, Orkney, Shetland and Tayside, illustrates less prescribing of these medications than would be expected. BOO, bladder outflow obstruction; GP,general practitioner.

notably Borders, Forth Valley, Tayside, Orkney and Shetland) compared with the average prescribing rate across Scotland. The reasons for these differences in prescribing pattern in these individual Health Boards are unclear and require further investigation.

Next, we examined the BOO drug-prescribing patterns of GP practices with the aim of assessing and visualising possible spatial patterns. Once again using the model residuals, it was possible to identify individual anonymous practices at the extremes of the BOO prescribing distribution and show their Health Board location on a map. This approach can be useful in order to detect geographic clusters of similar prescribing patterns, while accounting for temporal trends and other potential confounding factors that are already included in the model. For example, the policymaker might be interested in identifying clusters of GP practices where the rates of prescribing are either very low or very high with respect to the national average. We present the results of such analysis in figure 3 where, to preserve anonymity of the individual practices, we have aggregated the information at the Health Board level. We denote those GP practices with a model residual below the $2.5 \%$ percentile of the overall distribution of residuals as 'high-volume prescribers' and those above the $97.5 \%$ percentile as 'low-volume prescribers'. We stress that high-volume and low-volume are with respect to the national average as described by the model. Moreover, the quantile thresholds are arbitrary and can be adjusted according to the analytical need.

We observed that Highland is the Health Board with the largest percentage $(\sim 9.5 \%)$ of GP practices that were identified as being in the upper tail of prescribing volumes (identified by model residuals $<2.5 \%$ percentile), followed by Lothian ( $5.3 \%)$, Dumfries and Galloway $(\sim 3.2 \%)$, Grampian $(\sim 2.9 \%)$, Forth Valley $(\sim 2 \%)$ and Greater Glasgow and Clyde ( 1.7\%). No 'high-volume prescriber' GP practices were found within the remaining Health Boards. On the other hand, Tayside was identified as the Health Board with the largest percentage $(\sim 19 \%)$ of 'low-volume prescribers' (identified by model residuals $>97.5 \%$ percentile). Shetland (10\%), Borders $(\sim 8.7 \%)$, Grampian ( 5.7\%), Highland ( 1.1\%), Lothian $(\sim 1 \%)$ and Greater Glasgow and Clyde $(\sim 0.9 \%)$ also contained GP practices that prescribed far below the national average. The remaining Health Boards did not contain any 'low-volume prescribing' practices. The underlying 

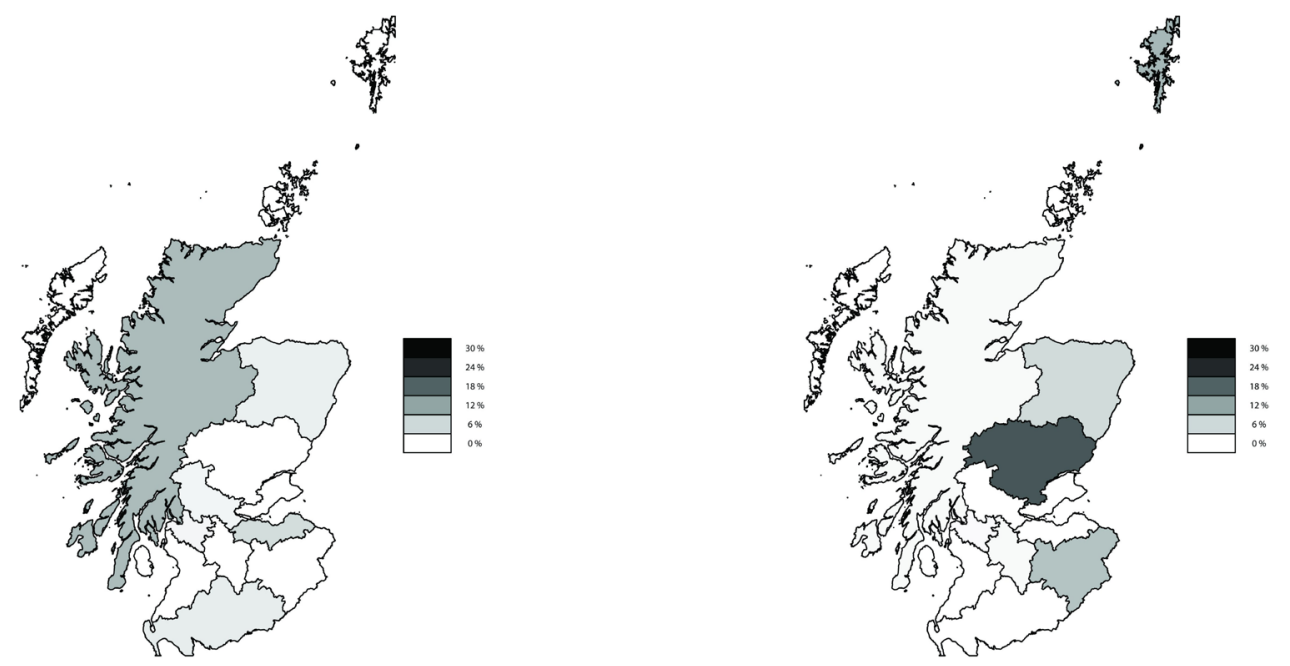

Figure 3 Maps of Scotland highlighting the Health Board locations of anonymous GP practices at the extremes of the distribution of $\mathrm{BOO}$ drug prescribing. The left panel shows the percentage of GP practices within each Health Board that have been identified (via model residuals) as being high in prescribing volumes with respect to the national average (ie, model residuals $<2.5 \%$ percentile). Similarly, the right panel shows the percentage of GP practices low in prescribing volumes with respect to the national average (ie, model residuals $>97.5 \%$ percentile). BOO, bladder outflow obstruction; GP, general practitioner.

reasons for these observations are currently unclear and require further investigation.

\section{DISCUSSION}

This study has investigated possible differences in patterns of medical prescribing for the two most common classes of drugs (ie, $\alpha-1$ blockers and $5-\alpha$ reductase inhibitors) used to treat BOO in Scotland over a recent 4-year period (October 2015-November 2019) using publicly available data from individual GP practices across all Health Boards. In taking this approach, we have assumed that most BOO medication is prescribed by GPs, either practising alone or on the advice of a specialist prescriber such as a urologist from specialist practice, as is the case throughout the UK. Nevertheless, using this approach and GP practice prescribing data with this assumption, we generated a study data set by linking prescribing data to GP practice-specific information (such as their type of contract with the NHS and their licence to dispense) and summary characteristics of their patient populations (such as patient age and GP practice-associated levels of deprivation and rurality). To our knowledge, this is the first time that particular characteristics of a GP practice have been studied as potential factors influencing BOO drug prescribing patterns in Scotland. This has enabled us to identify trends in prescribing behaviour that may help inform future practice.

A trend of increased $\mathrm{BOO}$ drug prescribing practice was observed throughout the 4-year observation window consistent with trends in increased detection of PCa (which is prevalent in men of the same age), an ageing Scottish population, increased awareness of male health issues among both patients and GPs and increased referral of men to secondary care due to a raised PSA. ${ }^{21} 22$ Though gaining a definite understanding of this trend was outside the scope of this study, in order to fully understand the nature of this increase, it would be pertinent to (1) identify the relative contribution (or otherwise) made by increased referral to secondary care with suspected PCa (as identified by a raised PSA), which might result in increased $\mathrm{BOO} / \mathrm{BPH}$ prescribing as a secondary consequence of a raised PSA referral, (2) the currently unaccounted for impact of increased GP and public awareness and public help seeking behaviour and (3) increased focus on PCa management, rather than BPH surgery, which may have contributed to the increase in medical drug use for BOO, rather than definitive intervention, though this is speculative. Greater understanding of these issues will facilitate planning to meet demand in primary care services given ongoing capacity shortage, and also secondary care as increased pharmacological treatment could be indicative of future demand for surgery. ${ }^{23}$

Whether practices were NHS or GP-run, or had a dispensing pharmacy present within the GP practice, were associated with higher and lower prescribing volumes, respectively. While the individual characteristics of GP medical practices are known to differ by region ${ }^{24}$ research accounting for these factors is relatively sparse; hence, it is unclear why this difference exists. Furthermore, although regional prescribing behaviours were largely uniform, lower levels of prescribing were noted in some individual Health Boards. No clear explanation could be given for this observation, as no possible explanatory factor is common to these Health Boards. An 
investigation of factors listed above would be pertinent to understand regional differences evident in prescribing behaviours and guide intervention to reduce inequity.

This study found several GP practices operating at the extremes of prescribing, with practices across five Health Boards prescribing considerably more, and practices across seven Health Boards prescribing considerably less, of each drug than other Scottish practices. In particular, 19\% of GP practices in Tayside were considered to be 'low-volume prescribers', which could partially explain why Tayside was found to have lower overall levels of prescribing. However, there was otherwise no correlation between individual GP practice prescribing behaviours and overall volume of prescriptions within the Health Board. As such, this study found that factors other than GP list size or accepted sociodemographic and geographic measures may be contributing to inequalities in prescribing practice. Further research is needed to identify these factors, although individual GP attitudes and understanding of prostate diseases, ${ }^{910}$ and Scotland's cultural diversity, ${ }^{78} 18$ may be potential explanations.

The data used in this research had several limitations. First, the available data only exist in the public domain at an aggregate level (ie, individual GP practice or patient list), and further information would be helpful in order to identify the reasons why prescribing practices vary at a more granular level (perhaps by associating the prescribing practice with the presence or absence of a GP with a particular interest in men's health issues, as an example). Second, the use of summary data regarding levels of socioeconomic deprivation and rurality of patients reduces the accuracy with which one can estimate the shape of their association with the outcome, with these factors likely to be important in terms of access to healthcare and prescribing. Third, not having information about specific GP practice catchment areas made it necessary to use an adjacency matrix based on postcodes, rather than actual distances, resulting in a suboptimal method of accounting for underlying spatial processes. Fourth, we have not investigated how differences in GP prescribing practices for $\mathrm{BOO}$ may impact on the rates of surgical management of this condition. For example, a study in Australia identified regional differences in the surgical management of $\mathrm{BOO}$ secondary to $\mathrm{BPH}^{23}$; it would be interesting for future research to potentially link BPH prescribing practice with rates of surgical management of this condition. For example, it might be the case that medical therapy can delay the need for surgery by a number of years, or reduced rates of $\mathrm{BPH}$ prescribing in any particular Health Board may be associated with higher rates of surgical intervention. These hypotheses require testing in data sets if they can be linked.

Further research to identify factors that lead to inequality in primary care practice is needed, and these is a need for data collection and data sharing to develop to enable this. It would also be interesting for future research to investigate trends and potential inequalities regarding all prostate-related conditions (both benign and malignant) over space and time in other settings and geographical locations. In particular, it would be interesting to investigate whether the trends observed in Scotland may similarly exist in other regions of the UK, and if so, are variations attributable to common factors such as urban/rural and socioeconomic status. In addition, the general nature of the statistical modelling framework we have proposed in this study may be extended to investigate other kinds of models, covariates and medical conditions in a range of future studies.

\section{CONCLUSIONS}

The volume of prescriptions of drugs for LUTS secondary to BOO has steadily increased across Scotland during a recent 4-year observation period, consistent with trends in PCa, which similarly affects men of this age. Regional differences in the volume of prescribed drugs, and extremes in individual GP practice prescribing patterns, were found. While prescribing patterns varied in relation to geographic and demographic factors and GP practice list size, this study identified considerable variations that could not easily be accounted for. Potential explanations for these variations include individual GP attitudes and understanding of prostate diseases ${ }^{9} 10$ and Scotland's cultural diversity. ${ }^{6-8}$

\section{Author affiliations}

${ }^{1}$ Health Sciences, University of Stirling, Stirling, UK

${ }^{2}$ Department of Surgical Sciences, University of Oxford Nuffield, Oxford, UK

${ }^{3}$ Urology, Churchill Hospital, Oxford, UK

${ }^{4}$ Lancaster Medical School, Lancaster University, Lancaster, UK

${ }^{5}$ GPPC, School of Medicine, Dentistry and Nursing, MVLS, University of Glasgow, Glasgow, UK

${ }^{6}$ School of Health Sciences, University of Dundee, Dundee, UK

Twitter Federico Andreis @Chicco_Stat and Andrea E Williamson @aewilliamsonl

Contributors FA and AW initiated the study. FA and EG developed the statistical model. FA had full access to all the data in the study, carried out the statistical analysis and took responsibility its accuracy and for the integrity of the data. FA drafted the manuscript, and all authors (FA, RB, EG, AEW, AW) contributed to the critical revision for important intellectual content, and to the interpretation of the data analysis results. RB and AEW provided advice on clinical aspects of the results.

Funding The authors have not declared a specific grant for this research from any funding agency in the public, commercial or not-for-profit sectors.

Map disclaimer The depiction of boundaries on this map does not imply the expression of any opinion whatsoever on the part of BMJ (or any member of its group) concerning the legal status of any country, territory, jurisdiction or area or of its authorities. This map is provided without any warranty of any kind, either express or implied.

Competing interests None declared.

Patient consent for publication Not required.

Provenance and peer review Not commissioned; externally peer reviewed.

Data availability statement Data are available in a public, open access repository. All data relevant to the study are included in the article or uploaded as supplementary information. A technical supplement, the statistical code (in R), and the final processed dataset used for the study available from GitHub: https://github. com/federicoandreis/prescribing_bmjopen/blob/main/README.md. The original, unprocessed data is publicly available online from the sources indicated in the manuscript in the Material and Methods section.

Supplemental material This content has been supplied by the author(s). It has not been vetted by BMJ Publishing Group Limited (BMJ) and may not have been 
peer-reviewed. Any opinions or recommendations discussed are solely those of the author(s) and are not endorsed by BMJ. BMJ disclaims all liability and responsibility arising from any reliance placed on the content. Where the content includes any translated material, BMJ does not warrant the accuracy and reliability of the translations (including but not limited to local regulations, clinical guidelines, terminology, drug names and drug dosages), and is not responsible for any error and/or omissions arising from translation and adaptation or otherwise.

Open access This is an open access article distributed in accordance with the Creative Commons Attribution Non Commercial (CC BY-NC 4.0) license, which permits others to distribute, remix, adapt, build upon this work non-commercially, and license their derivative works on different terms, provided the original work is properly cited, appropriate credit is given, any changes made indicated, and the use is non-commercial. See: http://creativecommons.org/licenses/by-nc/4.0/.

\section{ORCID iD}

Federico Andreis http://orcid.org/0000-0002-1776-3755

\section{REFERENCES}

1 European Association of Urology. EAU guidelines on non-neurogenic male LUTS, 2019.

2 Patel ND, Parsons JK. Epidemiology and etiology of benign prostatic hyperplasia and bladder outlet obstruction. Indian J Urol 2014;30:170-6.

3 Allemani C, Matsuda T, Di Carlo V, et al. Global surveillance of trends in cancer survival 2000-14 (CONCORD-3): analysis of individual records for 37513025 patients diagnosed with one of 18 cancers from 322 population-based registries in 71 countries. Lancet 2018;391:1023-75

4 NHS National Services Scotland. Cancer waiting times. NHS National Services Scotland, 2019.

5 Lee SWH, Chan EMC, Lai YK. The global burden of lower urinary tract symptoms suggestive of benign prostatic hyperplasia: a systematic review and meta-analysis. Sci Rep 2017;7:7984.

6 Taulbut M, Walsh D, McCartney G. Spatial inequalities in life expectancy within post-industrial regions of Europe: a crosssectional observational study. BMI Open 2014;4.

7 Walsh D, McCartney G, Collins C, et al. History, politics and vulnerability: explaining excess mortality in Scotland and Glasgow. Public Health 2017;151:1-12.

8 Cowley J, Kiely J, Collins D. Unravelling the Glasgow effect: the relationship between accumulative bio- psychosocial stress, stress reactivity and Scotland's health problems. Prev Med Rep 2016:4:370-5.

9 Public Health England. Prostate cancer risk management programme: overview, 2016.

10 Rai T, Clements A, Bukach C, et al. What influences men's decision to have a prostate-specific antigen test? A qualitative study. Fam Pract 2007;24:365-71.

11 Bajic P, Montgomery J, Nelson M. 133 comparisons Fo BPH medication prescribing among sexagenarians with Medicare an private insurance. J Sex Med 2020;17:37-8.

12 Fu Y, Han S, Wang L, et al. Comparison of characteristics of benign prostatic hyperplasia (BPH) patients treated with finasteride and alpha blocker combination therapy versus alpha blocker monotherapy in China: an analysis of electronic medical record data. Adv Ther 2018;35:1191-8.

13 Moon HW, Yang JH, Choi JB, et al. Prescription pattern of alphablockers for management of lower urinary tract symptoms/benign prostatic hyperplasia. Sci Rep 2018;8:13223.

14 Scottish Government. Scottish index of multiple deprivation [online]. Available: http://www.gov.scot/Topics/Statistics/SIMD [Accessed 9 Mar 2020].

15 Scottish Government. Scottish government urban rural classification. [online]. Available: https://www2.gov.scot/Topics/Statistics/About/ Methodology/UrbanRuralClassification [Accessed 9 Mar 2020].

16 National Institute for Health and Care Excellence. LUTS in men. National Institute for health and care excellence, 2019.

17 McConnell JD, Roehrborn CG, Bautista OM, et al. The long-term effect of doxazosin, finasteride, and combination therapy on the clinical progression of benign prostatic hyperplasia. N Engl J Med 2003;349:2387-98.

18 R Core Team. R: a language and environment for statistical computing. R foundation for statistical computing, Vienna, Austria, 2019. Available: https://www.R-project.org/

19 Rue H, Martino S, Chopin N. Approximate Bayesian inference for latent Gaussian models by using integrated nested Laplace approximations. J Royal Stat Soc Ser B 2009;71:319-92.

20 Andreis F. Github repository for code, data and shapefiles to reproduce the analyses in the paper. Available: https://github.com/ federicoandreis/prescribing_bmjopen/blob/main/README.md

21 National Records of Scotland. Mid-year population estimates Scotland, Mid-2018, 2019.

22 European Association of Urology. EAU guidelines on prostate cancer, 2019.

23 Morton A, Williams M, Perera M, et al. Management of benign prostatic hyperplasia in the 21st century: temporal trends in Australian population-based data. BJU Int 2020;126:18-26.

24 Burgess L. Primary care in Scotland. The Scottish Parliament, 2018. 